\title{
Difference in Hepatic Metabolism of Long- and Medium- Chain Fatty Acids: the Role of Fatty Acid Chain Length in the Production of the Alcoholic Fatty Liver*
}

\author{
Charles S. Lieber, +ł André Lefèvre, Norton Spritz, \\ Lawrence Fein man, $\|$ and Leonore M. DeCarli \\ (From the Liver Disease and Nutrition Unit, Second (Cornell) Medical Division, Bellevue \\ Hospital, and the Department of Medicine, Cornell University Medical College, \\ New York)
}

\begin{abstract}
Replacement of dietary triglycerides containing long-chain fatty acids (LCFA) by triglycerides containing medium-chain fatty acids (MCFA) markedly reduced the capacity of alcohol to produce fatty liver in rats. After 24 days of ethanol and MCFA, the increase in hepatic triglycerides was only 3 times that of controls, whereas an 8-fold rise was observed after ethanol and LCFA. The triglyceride fatty acids that accumulated in the liver after feeding of ethanol with MCFA contained only a small percentage of the MCFA; their composition also differed strikingly from that of adipose lipids.

To study the mechanism of the reduction in steatosis, we compared oxidation to $\mathrm{CO}_{2}$ and incorporation into esterified lipids of ${ }^{14} \mathrm{C}$-labeled chylomicrons or palmitate $-{ }^{14} \mathrm{C}$ (representing LCFA), and of octanoate $-{ }^{14} \mathrm{C}$ (as MCFA) in liver slices and isolated perfused livers, in the presence or absence of ethanol. Ethanol depressed the oxidation of all substrates to $\mathrm{CO}_{2}$; $\mathrm{MCFA}$, however, was much more oxidized and reciprocally much less esterified than LCFA, with a 100-fold difference in the ratio of esterified lipid- ${ }^{14} \mathrm{C}$ to ${ }^{14} \mathrm{CO}_{2}$. Furthermore, in hepatic microsomal fractions incubated with $\alpha$-glycerophosphate, octanoate was much less esterified than palmitate. This propensity of MCFA to oxidation rather than esterification represents a likely explanation for the reduction in alcoholic steatosis upon replacement of dietary LCFA by MCFA.
\end{abstract}

\section{Introduction}

We have shown previously, in man (2) and in rats $(3)$, that dietary fatty acids represent a large percentage of the triglyceride fatty acids that ac-

\footnotetext{
* Submitted for publication 20 March 1967; accepted 8 June 1967.

Presented in part at the Annual Meeting of the American Gastroenterological Association, Chicago, May 1966 and published in abstract form (1). This study was supported in part by U. S. Public Health Service research grants AM09536, AM10893, and AM06284 from the National Institute of Arthritis and Metabolic Diseases and grant NB03345-04 from the National Institute of Neurological Diseases and Blindness.

$\ddagger$ Recipient of a U. S. Public Health Service Research Career Development Award (K3-AM-22,590) from the National Institute of Arthritis and Metabolic Diseases.
}

cumulate in the liver after prolonged ingestion of alcohol ${ }^{1}$ with a normal diet containing LCT (triglycerides comprised of long-chain fatty acids).

$\S$ Established Investigator of the Health Research Council of the City of New York (I-128). Present address: The Rockefeller University, New York, N. Y.

\| Supported by a Postdoctoral Research Traineeship in Gastroenterology (TI AM 5091) and a Research Fellowship (F2 AM29096-01) from the National Institute of Arthritis and Metabolic Diseases, U. S. Public Health Service.

Address requests for reprints to Dr. Charles S. Lieber, Director, Liver Disease and Nutrition Unit, Second (Cornell) Medical Division, Bellevue Hospital, First Avenue and 26th Street, New York, N. Y. 10016.

1 In this paper, ethanol and alcohol are used synonymously. 


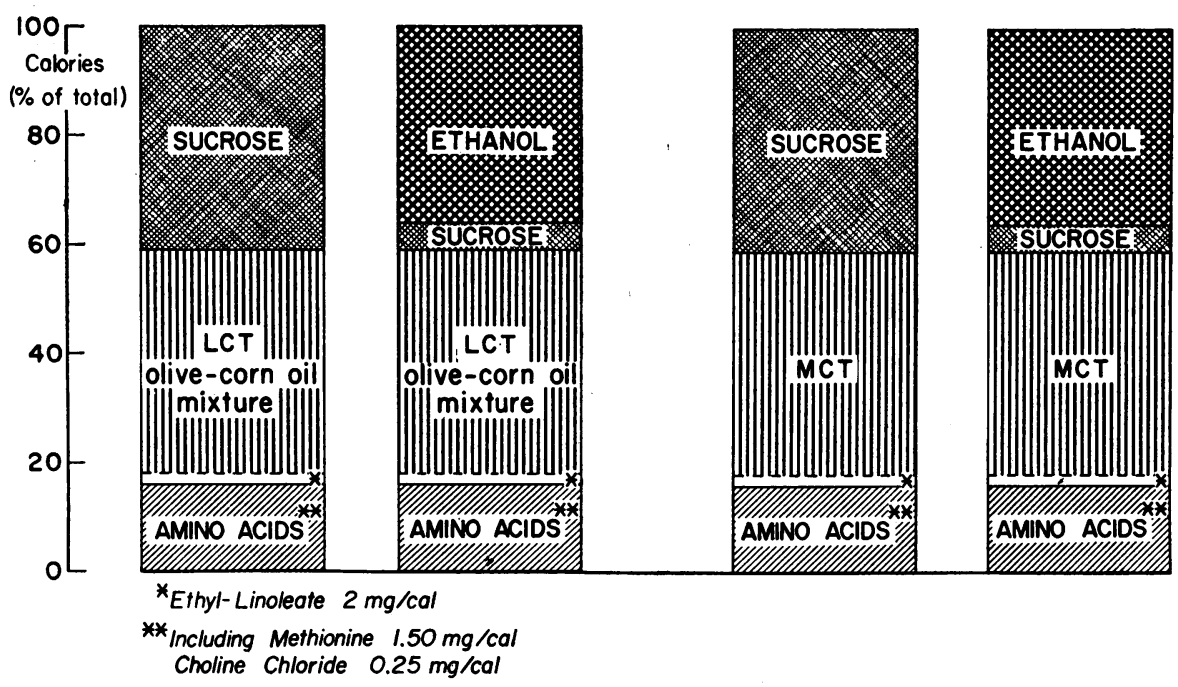

Fig. 1. SChematic Representation of the composition of the four isocaloric liquid DIETS FED TO RATS FOR 24 DAYS. LCT, triglycerides containing long-chain fatty acids; $M C T$, triglycerides containing medium-chain fatty acids.

When the dietary LCT were isocalorically replaced by MCT (triglycerides which consist of medium-chain fatty acids) it was noted, in a preliminary observation, that hepatic steatosis following alcohol ingestion was markedly reduced (4). In an attempt to explain this difference, we compared the hepatic metabolism of long-chain fatty acids (LCFA) and medium-chain fatty acids (MCFA) in the present study.

\section{Methods}

In vivo experiments. Charles River $\mathrm{CD}$ male rats ${ }^{2}$ were purchased in groups of four littermates each. They were maintained on Purina Laboratory Chow ${ }^{3}$ and tap water ad lib. until they reached a weight of $100-150 \mathrm{~g}$; they then were housed in individual wire-bottomed cages, and given liquid diets in Richter drinking tubes as the only source of food and water. The composition of the basic ethanol and control diets was as described before (5), except for the oil mixture. The latter consisted, per liter of diet, of $2 \mathrm{~g}$ of ethyl linoleate (supplemented with vitamin A acetate, $2 \mathrm{mg}$; calciferol, $10 \mu \mathrm{g} ; \alpha$-to copherol acetate, $30 \mathrm{mg}$ ), plus either $10.0 \mathrm{~g}$ of corn oil and $34.3 \mathrm{~g}$ of olive oil given as a source of LCFA to half the rats or $49.5 \mathrm{~g}$ of $\mathrm{MCT}^{4}$ given alternatively as a

2 Purchased from Charles River Breeding Laboratories, Inc., North Wilmington, Mass.

${ }^{3}$ Purchased from Ralston Purina Co., St. Louis, Mo.

${ }^{4}$ MCT was kindly provided by Drew Chemical Corp., Boonton, N. J. source of MCFA to the other half of the animals. For the isocaloric replacement of the olive-corn oil mixture by MCT, the latter was considered to have a caloric value of $8.0 \mathrm{cal} / \mathrm{g}^{5}$ The animals were studied in groups of four littermates each. Two of the littermates received the LCT and MCT control diets respectively, while the other two were given the same diets in which carbohydrates were progressively and isocalorically replaced by ethanol, as described previously (5). A schematic representation of the four diets is given in Fig. 1. Each litter of four animals was group-fed daily; the volume of liquid diet was limited to the intake of the member with the lowest consumption.

After 24 days, the animals were sacrificed by decapitation and the liver and epididymal fat pads were quickly excised. Total lipid and triglyceride concentrations in the liver (4) and fatty acid composition of the hepatic triglycerides and of the adipose tissue lipids (3) were determined as described previously, except that in order to avoid loss of MCFA, evaporation of solvents was carried out at room temperature. Recovery of MCT added to the original lipid extract varied between 85 and $93 \%$.

Liver perfusion experiments. Isolated rat livers were perfused according to the technique of Miller, Bly, Watson, and Bale (6), using heparinized rat blood diluted (2:1) with a Ringer ${ }^{6}$ solution to which bicarbonate had been added (final concentration: $30 \mathrm{mEq} /$ liter). Precautions were taken according to Kay and Entenman

\footnotetext{
5 Drew Chemical Corp., Boonton, N. J. Personal communication.

6 Purchased from Abbott Laboratories, North Chicago,
} IIl. 
(7) to avoid injection of heparin into the rats from which blood, lymph, or liver was obtained. Glucose was added to achieve a final concentration of $150 \mathrm{mg} / 100 \mathrm{ml}$. The perfusions were carried out in paired experiments, with or without ethanol; for each member of the pair, equal volumes of the same perfusate, ranging from 100 to $135 \mathrm{ml}$, were used. The gas phase consisted of a mixture of $\mathrm{O}_{2}(98 \%)$ and $\mathrm{CO}_{2}(2 \%)(\mathrm{v} / \mathrm{v})$.

2-hr before the perfusion, the rats whose livers were used for the ethanol experiments were given $2-2.4 \mathrm{~g} / \mathrm{kg}$ ethanol, by gastric tube, while the corresponding control rats received an isocaloric amount of carbohydrate.

At the onset of the perfusion, a loading dose of ethanol was added to achieve an initial concentration of $200 \mathrm{mg} /$ $100 \mathrm{ml}$. Thereafter, half the initial ethanol dose was given hourly to maintain the alcohol concentration throughout the experiment at a level of $50-100 \mathrm{mg} / 100 \mathrm{ml}$ of perfusate. Three groups of three to four paired perfusions each were performed with the addition of:

(a) ${ }^{14}$ C-labeled chylomicrons, obtained as described previously (3), including the avoidance of procedures apt to alter the chylomicrons, such as chilling. Chylomicron lipid was $1.07-3.07 \mathrm{mg} / \mathrm{ml}$ of final perfusate with approximately $200,000 \mathrm{dpm} / \mathrm{mg}$ of lipid. Approximately $2 \%$ of the label was in free fatty acids, $2 \%$ in phospholipids, and the remainder in triglycerides.

(b) ${ }^{14} C$-labeled LCFA (palmitate- $1-{ }^{14} \mathrm{C}$ ), ${ }^{7}$ bound to albumin (8), added at a concentration of $0.03-0.05 \mu \mathrm{Eq} /$ $\mathrm{ml}$ of perfusate $(0.27-0.38 \mu \mathrm{c} / \mathrm{ml})$. To equalize the lipid loads, we performed half of the perfusions with addition of nonlabeled chyle in amounts similar to those of the experiments in which ${ }^{14} \mathrm{C}$-labeled chylomicrons were perfused. Unlabeled, albumin-bound palmitic acid (0.38 $\mu \mathrm{Eq} / \mathrm{ml}$ ) was added to the perfusions that did not contain chylomicrons.

(c) ${ }^{14} C$-labeled $M C F A$ (octanoate- $1-{ }^{14} \mathrm{C}$ ) ${ }^{7}$ added at a final concentration of $0.78 \mu \mathrm{Eq} / \mathrm{ml}(0.26 \mu \mathrm{c} / \mathrm{ml})$, with albumin in an amount equal to that used with palmitate${ }^{14} \mathrm{C}$. The fatty acid load (in milligrams) of these experiments was comparable to that of the perfusions with palmitate ${ }^{14} \mathrm{C}$ (supplemented with nonlabeled palmitic acid).

In all instances, the labeled lipid material was added after a control period of $30 \mathrm{~min}$ during which the adequacy of the perfusion was judged by the continuous excretion of bile and by the blood flow, which averaged $1.79 \pm 0.17 \mathrm{ml} / \mathrm{g}$ of liver per $\mathrm{min}$.

$\mathrm{CO}_{2}$ was collected in a $100 \mathrm{ml}$ trap of $2 \mathrm{~N}$ sodium hydroxide solution, renewed every $30 \mathrm{~min}$. Aliquots were suspended with a thixotropic gel powder (Cab-O-Sil) ${ }^{8}$ (9) and ${ }^{14} \mathrm{CO}_{2}$ radioactivity was determined in a liquid scintillation counter (10). In three pairs of perfusions (two with chylomicron- ${ }^{14} \mathrm{C}$, one with palmitate- ${ }^{14} \mathrm{C}$ ) total $\mathrm{CO}_{2}$ was measured repeatedly by the procedure of Van Slyke (11) in the in- and outflow blood of the liver and the total $\mathrm{CO}_{2}$ produced was calculated from the difference

\footnotetext{
${ }^{7}$ Purchased from New England Nuclear Corp., Boston, Mass.

8 Purchased from Packard Instrument Co., Inc., Downers Grove, Ill.
}

in $\mathrm{CO}_{2}$ concentrations and the blood flow rates. The duration of the perfusion varied between 2 and $4 \mathrm{hr}$. At the end of the perfusion, livers were flushed with saline and weighed. Total lipids were extracted from the liver as described for the in vivo studies and phospholipids were separated from the neutral lipids by silicic acid column chromatography as described previously (3).

Aliquots of the liver were also taken for protein determination (12) in order to express the results as a function of the protein content.

Ethanol concentration in the perfusion medium was determined by the procedure of Bonnichsen (13).

Liver slice experiments. These studies were conducted in five series of four incubation flasks each. Liver slices, obtained as described previously (10), were randomly distributed among the four flasks at approximately $0.5 \mathrm{~g}$ per flask. The incubation medium was as described previously $(10)$, with added albumin $(4 \mathrm{~g} / 100 \mathrm{ml})$. To two of the flasks, palmitate- $1-{ }^{14} \mathrm{C}$, bound to albumin (8), was added at a concentration of $0.2 \mu \mathrm{mole} / \mathrm{ml}(0.4 \mu \mathrm{c} /$ $\mathrm{ml})$; the two other flasks received, instead of palmitate$1-{ }^{14} \mathrm{C}$, octanoate- $1-{ }^{14} \mathrm{C}$, at a final concentration of 0.4 $\mu \mathrm{mole} / \mathrm{ml}(0.4 \mu \mathrm{c} / \mathrm{ml})$. To half the flasks, ethanol was added at a final concentration of $10 \mu$ moles $/ \mathrm{ml}$, while the other flasks received, as control substrate, $10 \mu \mathrm{moles} / \mathrm{ml}$ of acetate.

After a $3 \mathrm{hr}$ incubation period, ${ }^{14} \mathrm{CO}_{2}$ produced was collected and counted as described previously (10). The liver slices were washed with saline twice; total lipids were extracted and neutral lipids and phospholipids separated as described above in the perfusion experiments.

Labeling of the lipid fractions was determined in a liquid scintillation counter as described previously (10).

Experiments with hepatic microsomes. The microsomal fraction was obtained by ultracentrifugation according to Stein and Shapiro (14). It was then incubated at $37^{\circ} \mathrm{C}$ in a shaking water bath with palmitate or octanoate $(0.2-1.2 \mu$ moles $/ 3 \mathrm{ml})$, glycerophosphate ${ }^{-14} \mathrm{C} \quad(10$ $\mu$ moles, $0.5 \mu \mathrm{c} / 3 \mathrm{ml}),{ }^{9}$ and the necessary cofactors for esterification, in the medium described by Stein and Shapiro (14); the fatty acid concentration range was extended to the limit of solubility of palmitate. Simultaneously, blank incubations were performed in the absence of microsomes. At the end of $30 \mathrm{~min}$, total lipids were extracted (15) and the amount of esterified $\alpha$-glycerophosphate was assessed by the radioactivity of the lipid extract corrected for the blank value and expressed per milligram of microsomal protein. Protein was measured according to Lowry, Rosebrough, Farr and Randall (16) and radioactivity was determined as described above.

In all experiments, each individual result was compared to its corresponding control, and the mean of the individual differences was tested by the Student $t$ test (17). The variance of the means was estimated by the standard error.

${ }^{9}$ Purchased as $1-\alpha$-glycerol-U- ${ }^{14} \mathrm{C}$ phosphate from International Chemical and Nuclear Corporation, City of Industry, Calif. 


\section{Results}

In vivo experiments. As indicated in Fig. 2, both groups of rats given ethanol had a significant increase of hepatic triglycerides, in comparison with their respective controls. This increase, however, was much less pronounced after ethanolMCT (3-fold triglyceride rise; $P<0.02$ ) than ethanol-LCT (8-fold rise ; $P<0.001$ ), with a significant difference between the groups $(P<0.01)$. The total lipids had similar changes: $48.1 \pm 4.2$ $\mathrm{mg} / \mathrm{g}$ in the LCT control, $118.8 \pm 13.1 \mathrm{mg} / \mathrm{g}$ in the LCT-ethanol, $54.0 \pm 2.9 \mathrm{mg} / \mathrm{g}$ in the MCT control, and $72.0 \pm 7.4 \mathrm{mg} / \mathrm{g}$ in the MCT-ethanol groups. These results indicate that the bulk of the total lipid changes can be accounted for by the accumulation of triglyceride.

In Fig. 3, we have represented the composition of the major fatty acids of the hepatic triglycerides, which accumulated in the rats given MCT-ethanol, together with that of the corresponding adipose tissue. The fatty acids of the hepatic triglycerides contained only a small percentage of MCFA, but comprised instead a large amount of endogenously synthesized LCFA such as palmitate and oleate. The fatty acid composition of the hepatic tri- glycerides differed also from that of adipose tissue in two respects: adipose lipids had a greater proportion of MCFA than liver triglycerides; furthermore the linoleate concentration of adipose lipids ( $15.6 \pm 1.5 \%$ of total fatty acids) was much higher than that of liver triglycerides $(5.6 \pm$ $1.5 \%)$. In the rats given the MCT control diet, similar findings were observed, except for a lower hepatic triglyceride concentration.

Liver perfusion experiments. In the three experiments in which alcohol was added to the ${ }^{14} \mathrm{C}$ labeled chylomicrons in the perfusion media, the production of total ${ }^{14} \mathrm{CO}_{2}$ was markedly depressed from average control values of 40,500 dpm (per $100 \mathrm{mg}$ of liver protein) to $5060 \mathrm{dpm}$ after ethanol. This is illustrated for one pair of studies in Fig. 4. As indicated in Fig. 5, a comparable depression of ${ }^{14} \mathrm{CO}_{2}$ production was observed from free fatty acids, both long-chain (palmitate- ${ }^{14} \mathrm{C}$ ) and medium-chain (octanoate $-{ }^{14} \mathrm{C}$ ). In the livers perfused with palmitate- ${ }^{14} \mathrm{C}$ and unlabeled chylomicrons (Fig. 5, center panel, solid lines), the ${ }^{14} \mathrm{CO}_{2}$ produced was depressed from an average 722,600 $\mathrm{dpm} / 100 \mathrm{mg}$ of liver protein in the controls to $94,000 \mathrm{dpm}$ in the ethanol studies, while the corresponding values in the perfusions with palmi-

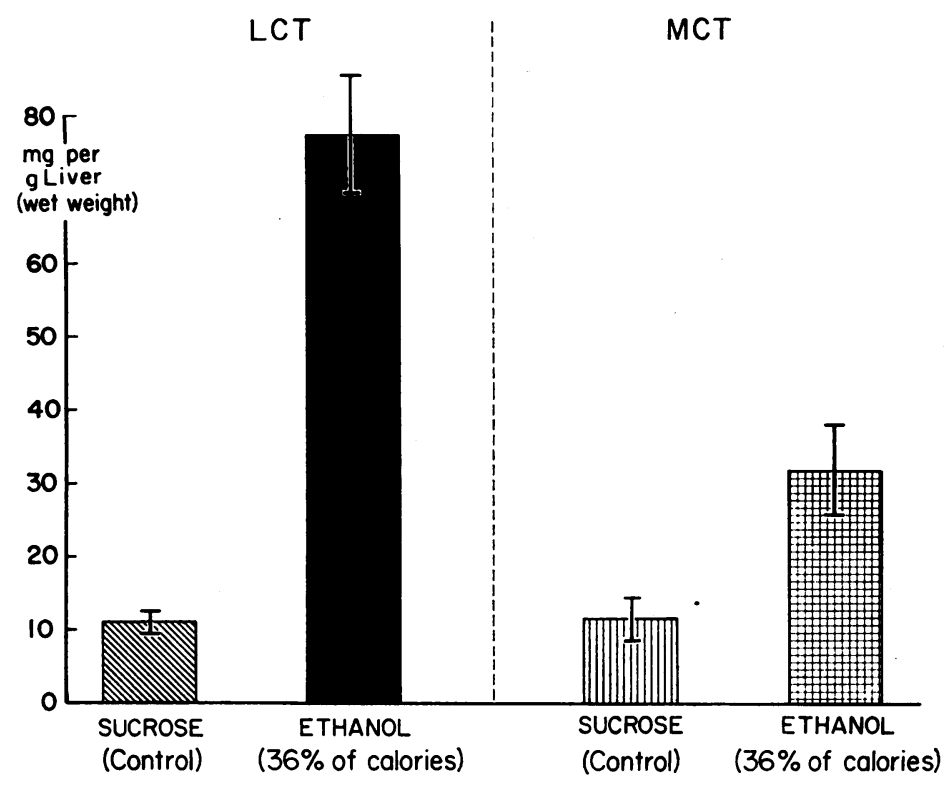

Fig. 2. EFfeCt of isocaloric substitution of LCT by MCT on HEPATIC TRIGLYCERIDE ACCUMULATION. The rats were fed isocaloric liquid diets for 24 days, with $41 \%$ of calories as long-chain triglycerides ( $L C T$, olive-corn oil mixture), or medium-chain triglycerides $(M C T)$. 

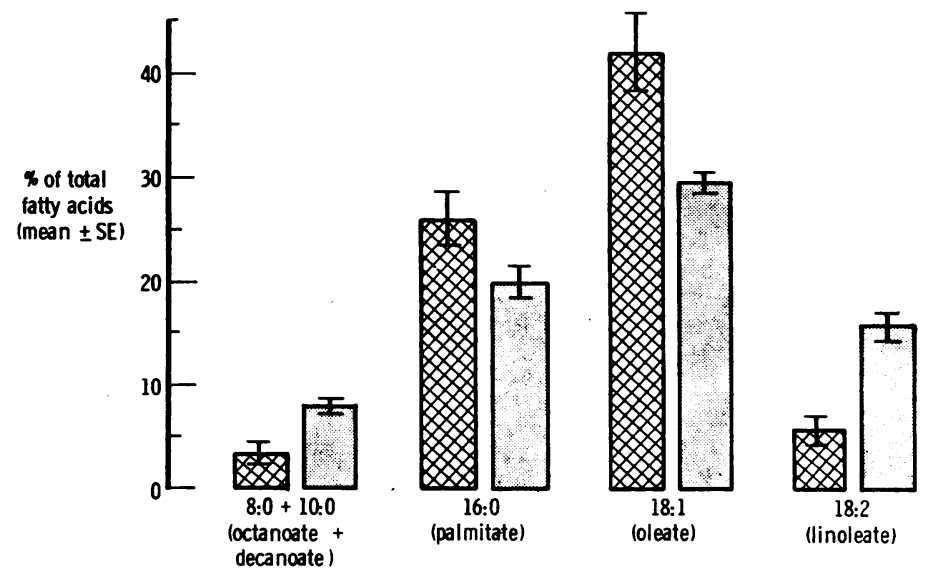

Fig. 3. COMPARISON OF FATTY ACID COMPOSITION OF ADIPOSE LiPIDS (DOTTED BARS) AND LIVER TRIGLYCERIDES (CROSS-HATCHED BARS) IN RATS FED ETHANOL AND MCT-Containing DIETS OVER 24 DAYs. A similar fatty acid composition was observed in the control animals; their hepatic triglyceride concentrations, however, were lower (see Fig. 2).

tate- ${ }^{14} \mathrm{C}$ and unlabeled palmitic acid (Fig. 5, center panel, dashed lines) were 213,600 and 45,100 $\mathrm{dpm}$, respectively. In the perfusions with octanoate, the corresponding values were 750,700 and $283,700 \mathrm{dpm}$, respectively. That this reduction in ${ }^{14} \mathrm{CO}_{2}$ produced from various substrates upon addition of ethanol is not solely due to isotopic dilution by metabolites of alcohol is indicated by the observation that, when measured, total $\mathrm{CO}_{2}$ production was also found to be depressed, from 0.65 $\pm 0.15 \mu \mathrm{mole} / \mathrm{min}$ (per $100 \mathrm{mg}$ of liver protein) in the control perfusions to $0.20 \pm 0.03$ in the ethanol experiments.

The per cent recovery (for the total duration of the control experiments) in ${ }^{14} \mathrm{CO}_{2}$ of the lipid label administered was much lower when ${ }^{14} \mathrm{C}$-labeled chylomicrons were used $(0.3-2.3 \%)$, than when palmitate- ${ }^{14} \mathrm{C}(3-10 \%)$ or octanoate- ${ }^{14} \mathrm{C}$ $(10-12 \%)$ was perfused.

No consistent difference was found between the alcohol and control perfusions in the absolute amount of label recovered in the neutral lipid or phospholipid fractions. The average absolute values of radioactivity recovered in the hepatic neutral lipids and phospholipids were 171,400 and $93,200 \mathrm{dpm}$ (per $100 \mathrm{mg}$ of liver protein) in the perfusion with ethanol and ${ }^{14} \mathrm{C}$-labeled chylomicrons; the corresponding controls were 198,500 and $124,400 \mathrm{dpm}$. In the perfusions with ethanol, palmitate ${ }^{14} \mathrm{C}$, and unlabeled chylomicrons, the radioactivity in hepatic neutral lipids and phospholipids was $1,811,100$ and 2,673,100 dpm (per $100 \mathrm{mg}$ of liver protein), respectively; the corresponding controls were $1,640,700$ and $2,191,100$ $\mathrm{dpm}$. In the perfusions with ethanol, palmitate-

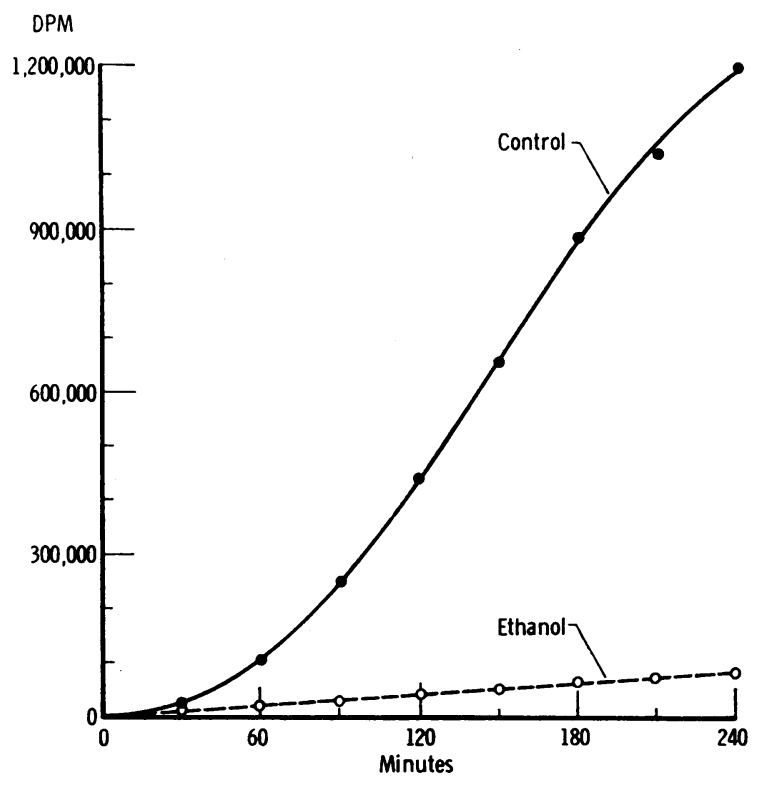

Fig. 4. EFFect of alcohol on total ${ }^{14} \mathrm{CO}_{2}$ PRODUCtion FROM ${ }^{14}$ C-LABELED CHYLOMICRONS IN A PAIR OF ISOLATED PERFUSED RAT LIVERS. 


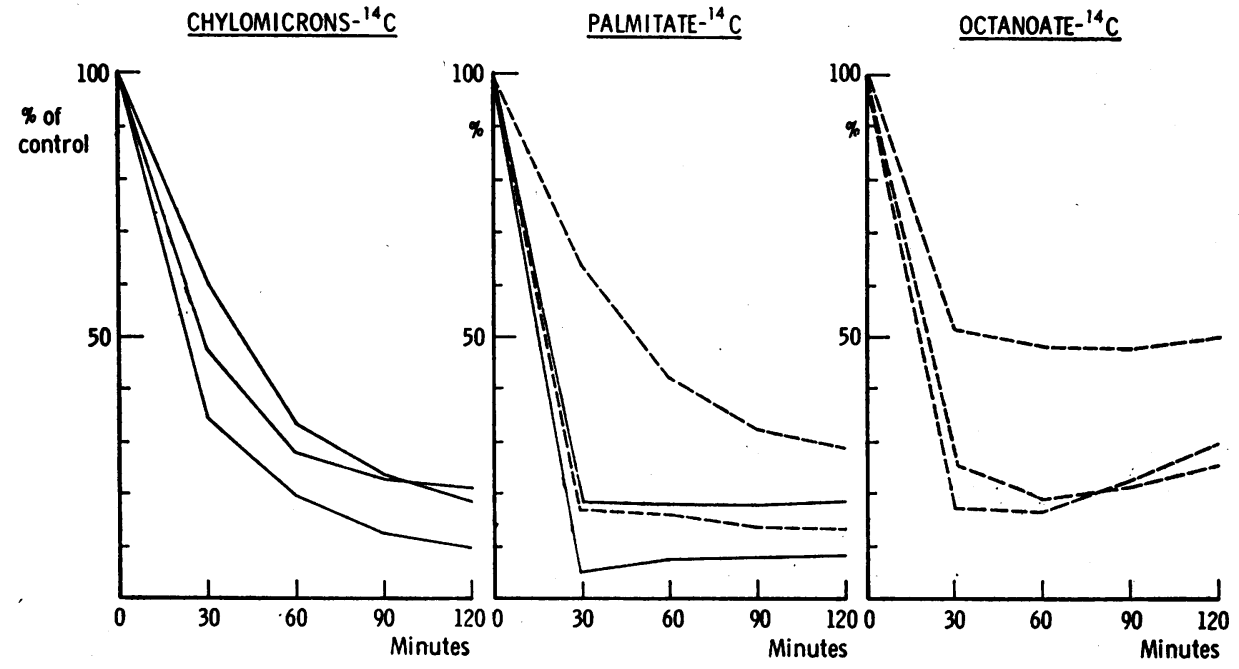

Fig. 5. Comparison of the efFect of ethanol on ${ }^{14} \mathrm{CO}_{2}$ PRODUCtion From either ${ }^{14} \mathrm{C}$ LABELED CHYLOMICRONS, PALMITATE, OR OCTANOATE. In the palmitate- ${ }^{14} \mathrm{C}$ experiments indicated by a solid line, unlabeled chylomicrons (in amounts comparable to those used in the studies with ${ }^{14} \mathrm{C}$-labeled chylomicrons) were added to the perfusate; in the palmitate- ${ }^{14} \mathrm{C}$ experiments indicated by a dashed line, unlabeled palmitic acid $(0.38 \mu \mathrm{Eq} / \mathrm{ml})$ was added.

${ }^{14} \mathrm{C}$, and unlabeled palmitic acid; the radioactivity in hepatic neutral lipids and phospholipids was $1,260,400$ and $796,000 \mathrm{dpm}$, respectively (controls : $982,200$ and $1,151,200 \mathrm{dpm})$; the corresponding values in the perfusions with octanoate- ${ }^{14} \mathrm{C}$ were 122,100 and $45,600 \mathrm{dpm}$ with ethanol and 110,600 and $57,900 \mathrm{dpm}$ in the controls.

The above results of incorporation of ${ }^{14} \mathrm{C}$ in

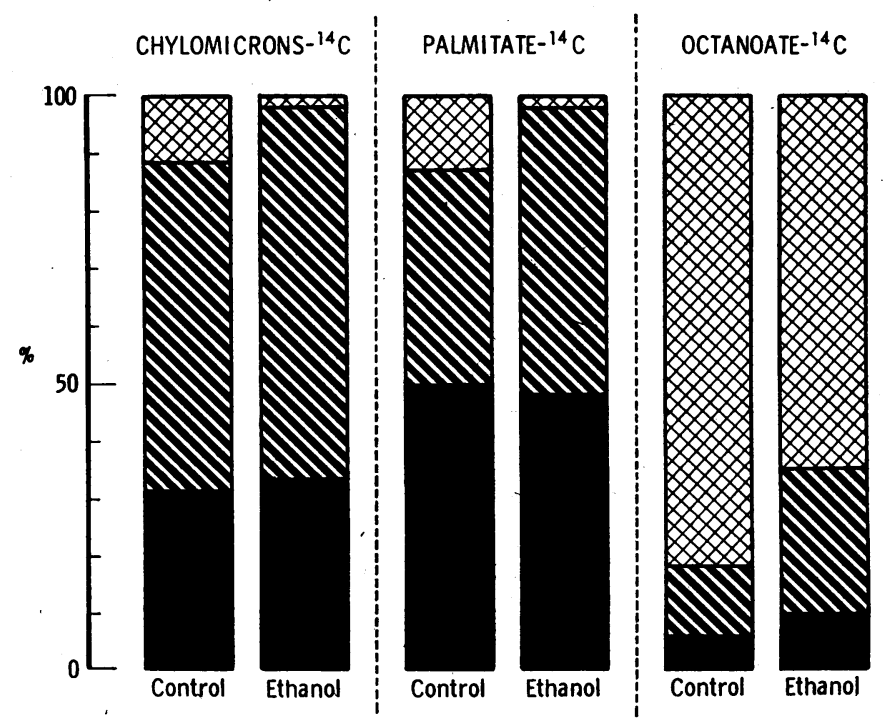

Fig. 6. Comparison of the inCORPORATION INTO hePATIC NEUTRAL LIPIDS (STRIATED AREAS), PHOSPHOLIPIDS (SOLID AREAS), AND $\mathrm{CO}_{2}$ (CROSS-HATChed AREAS) OF THE ${ }^{14} \mathrm{C}$-LABEL DERIVEd From ISOLATED LIVERS PERFUSED WITH CHYLOMICRONS $-{ }^{14} \mathrm{C}$, PALMITATE $-{ }^{14} \mathrm{C}$, AND OCTANOATE $-{ }^{14} \mathrm{C}$. The radioactivity of each fraction is expressed as percentage of the total labeling recovered in these three major fractions. 


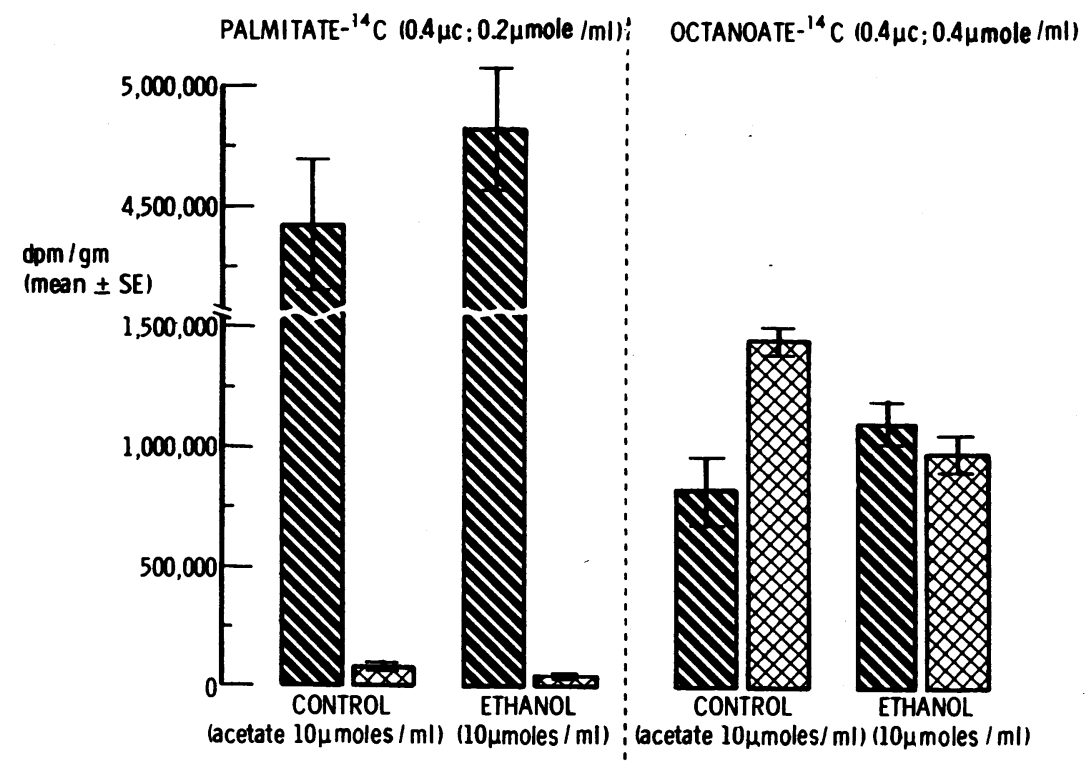

Fig. 7. Comparison of the incorporation into hepatic total Lipids $-{ }^{14} \mathrm{C}$ (STRIATED BARS) AND $\mathrm{CO}_{2}$ (CROSS-HATCHED BARS) OF THE LABEL DERIVED FROM PALMITATE- ${ }^{-14} \mathrm{C}$ AND OCTANOATE- ${ }^{14} \mathrm{C}$, IN LIVER SLICES INCUBATED FOR 3 HR WITH ETHANOL OR ACETATE.

$\mathrm{CO}_{2}$ and lipids reveal the striking find that the relative distribution of the label between esterified lipids and ${ }^{14} \mathrm{CO}_{2}$ was very different depending on the chain length of the fatty acids used. With ${ }^{14} \mathrm{C}$-labeled chylomicron and palmitate, much more of the label was present in the esterified lipids than in ${ }^{14} \mathrm{CO}_{2}$ (in the control experiments as well as in those with addition of ethanol), whereas the reverse was true in the studies with octanoate $-{ }^{14} \mathrm{C}$ (Fig. 6). As a result, after ethanol, the ratio of labeled esterified lipids to ${ }^{14} \mathrm{CO}_{2}$ was approximately a hundred times lower in experiments with labeled MCFA $(0.59 \pm 0.17)$ than with labeled LCFA (palmitate: $47.0 \pm 7.2$; chylomicron : $52.0 \pm 11.5)$.

Liver slice experiments. As illustrated in Fig. 7 , ethanol lowered ${ }^{14} \mathrm{CO}_{2}$ production from both labeled LCFA and MCFA. Furthermore, in absolute amounts, there was a 25 -fold greater oxidation to ${ }^{14} \mathrm{CO}_{2}$ from the MCFA (octanoate- ${ }^{14} \mathrm{C}$ ) than from the LCFA (palmitate- $\left.{ }^{14} \mathrm{C}\right) \quad(P<$ 0.001 ). In contrast, incorporation into hepatic neutral lipids and phospholipids was about 4 times less with octanoate than with palmitate. The neutral lipid labeling was $901,600 \pm 168,700$ and $4,310,800 \pm 138,900 \mathrm{dpm} / \mathrm{g}$ of liver in the slices incubated with ethanol and octanoate or palmitate, respectively $(P<0.001)$; the corresponding values for phospholipids were $123,700 \pm 66,300$ and $413,000 \pm 28,600$, respectively $(P<0.001)$. Incorporation of palmitate and octanoate in the hepatic lipids appeared increased by ethanol (Fig. 7 ), but because of variability in the results, the differences were not statistically significant.

Microsome experiments. As shown in Table I, despite marked variations in activity between different microsomal preparations, more radioactivity

TABLE I

Radioactivity in esterified lipids after incubation of $\alpha$-glycerophosphate- ${ }^{14} \mathrm{C}$ with either octanoic acid or palmitic acid*

\begin{tabular}{|c|c|c|c|}
\hline $\begin{array}{l}\text { Micro- } \\
\text { somal } \\
\text { prepa- } \\
\text { ration }\end{array}$ & $\begin{array}{l}\text { Fatty } \\
\text { acid } \\
\text { concen- } \\
\text { tration }\end{array}$ & $\begin{array}{c}\text { Octanoic } \\
\text { acid }\end{array}$ & $\begin{array}{c}\text { Palmitic } \\
\text { acid }\end{array}$ \\
\hline A & $\begin{array}{c}\mu \text { mole } / \mathrm{ml} \\
0.07\end{array}$ & 658 & 3240 \\
\hline B & 0.20 & 776 & 3697 \\
\hline C & $\begin{array}{l}0.07 \\
0.20\end{array}$ & $\begin{array}{l}607 \\
622\end{array}$ & $\begin{array}{l}2782 \\
4534\end{array}$ \\
\hline D & $\begin{array}{l}0.07 \\
0.20 \\
0.40\end{array}$ & $\begin{array}{l}596 \\
564 \\
500\end{array}$ & $\begin{array}{l}1072 \\
1613 \\
3198\end{array}$ \\
\hline
\end{tabular}

* $\mathrm{dpm} / \mathrm{mg}$ of protein; $30 \mathrm{~min}$ incubation according to Stein and Shapiro (14). 
appeared in esterified lipids when $\alpha$-glycerophosphate $-{ }^{14} \mathrm{C}$ was incubated with palmitate than with octanoate, in any given microsomal fraction for all concentrations tested. For the same microsomal preparation, even when the octanoate concentration was 6-fold that of palmitate, esterification was still markedly lower (Table I).

\section{Discussion}

Our study shows that when dietary LCT are replaced by MCT, fatty liver produced by alcohol is markedly decreased (Fig. 2) and the hepatic triglycerides have a negligible content of dietary MCFA (Fig. 3). This contrasts with the fatty liver resulting from the feeding of ethanol and LCT, which was found to contain triglycerides with a high percentage of dietary fatty acids $(2,3)$. The triglycerides of the ethanol-MCT fatty liver also had a fatty acid composition markedly different from that of adipose tissue, with much less linoleate and significantly less octanoate and decanoate (Fig. 3). These findings suggest that the triglyceride fatty acids that accumulate in the liver after ethanol-MCT diets do not derive primarily from either adipose or dietary lipids, but may represent endogenously synthesized fatty acids. The observed composition is similar to that of hepatic triglycerides in fatty liver produced by ethanol and low fat, high carbohydrate diets (2, 3 ). The possibility has not been ruled out, however, that in the present study, some of the accumulation of LCFA in the liver may have resulted from elongation of MCFA. Quantitatively, however, this possibility is probably of minor significance, in view of the observation that elongation of octanoate occurs only to a minimal degree in the liver (18).

As a possible explanation for the difference in hepatic accumulation of MCFA and LCFA, consideration must be given first to differences in their metabolic pathways. In contrast with MCFA, which, after intestinal absorption, are carried primarily as free carboxylic acids by the portal route to the liver $(19,20)$, LCFA are absorbed as chylomicrons via the lymphatic channels (19, 20 ). The difference in the hepatic fat accumulation after ethanol-LCT and ethanol-MCT, however, does not appear to result from a specific effect of ethanol on chylomicron metabolism : a com- parable depression of oxidation of the lipids in the liver was observed with either chylomicrons or free fatty acids (Fig. 5). Furthermore, we found previously that ethanol does not alter hepatic uptake of chylomicron (3).' Moreover, whether under normal circumstances the liver metabolizes circulating chylomicrons per se or whether they are first hydrolyzed in the vascular space or in peripheral tissues is the subject of controversy (21-24). Consistent with the latter possibility is our observation of a low rate of oxidation of ${ }^{14} \mathrm{C}$-labeled chylomicrons to ${ }^{14} \mathrm{CO}_{2}$, compared to that of the oxidation of ${ }^{14} \mathrm{C}$-labeled fatty acids. The amount of ${ }^{14} \mathrm{CO}_{2}$ and ${ }^{14} \mathrm{C}$-labeled phospholipids recovered in the livers perfused with ${ }^{14} \mathrm{C}$-labeled chylomicrons was too high, however, to be accounted for entirely by the small percentages of labeled free fatty acids and phospholipids initially present in the chylomicron preparation. This means, as was also concluded recently by other investigators $(23,24)$, that some hydrolysis of chylomicron triglyceride must have taken place, but does not indicate whether this reaction occurred at intra- or extracellular sites. Although lipoprotein lipase has been demonstrated in the dog liver (25), whether or not lipoprotein lipase exists in the rat liver and contributes to chylomicron lipolysis is the subject of controversy. According to most authors, the rat liver does not contain any lipoprotein lipase (26-28), while Mayes and Felts (29) describe some activity in response to large doses of heparin. Since heparin was used in the liver perfusions of the present study, it conceivably could have played some role in the breakdown of chylomicrons to free fatty acids.

It has been shown that ethanol oxidation in the liver results in the production of nearly equimolar amounts of acetate (30). This could result in a depression of ${ }^{14} \mathrm{CO}_{2}$ production through isotopic dilution of an acetylCoA- $-{ }^{14} \mathrm{C}$ intermediate produced during the metabolism of the ${ }^{14} \mathrm{C}$-labeled lipid precursors. The possibility, however, that this accounts solely for the ${ }^{14} \mathrm{CO}_{2}$ reduction has been ruled out in the liver perfusion experiments in which both ${ }^{14} \mathrm{CO}_{2}$ and total $\mathrm{CO}_{2}$ production were found to be depressed by ethanol. The depression of ${ }^{14} \mathrm{CO}_{2}$ and $\mathrm{CO}_{2}$ production suggests that ethanol may reduce the activity of the citric acid cycle (31) ; this reduced activity may, in turn, contribute 
to the hepatic accumulation of LCFA observed after ethanol $(2,3)$.

In liver perfusions as well as in liver slices, whether or not alcohol was added, the relative distribution of the label between esterified lipids and ${ }^{14} \mathrm{CO}_{2}$ was greatly affected by the chain length of the available fatty acid (Figs. 6 and 7 ). Much more of the label from palmitate- ${ }^{14} \mathrm{C}$ was recovered in neutral lipids or phospholipids than in $\mathrm{CO}_{2}$, whereas the reverse was true for octanoate${ }^{14} \mathrm{C}$. Although ethanol depressed ${ }^{14} \mathrm{CO}_{2}$ production in both instances, it did not significantly affect the basic difference in behavior of the fatty acids of different chain length.

It has been shown that the hepatic enzyme system responsible for esterification of fatty acids to more complex lipids (i.e., triglycerides and phospholipids) has a much greater affinity for 16 and 18 carbon fatty acids than for shorter, 12 and 14 , carbon chains (32). The present study indicates that this can be extrapolated to octanoate, an eight carbon MCFA. A similar difference in esterification of palmitate and octanoate has been described previously in intestinal tissue (33). The difference in the hepatic oxidation of LCFA and MCFA which we observed in the present study may actually result from the reciprocal difference in esterification. The high rate of hepatic oxidation of MCFA could, in turn, be responsible for the relative lack of their accumulation in hepatic triglycerides, even when administered with ethanol.

In conclusion, the present study demonstrates a fundamental difference in hepatic metabolism of fatty acids depending on their chain length: MCFA (even in the presence of alcohol) were observed to be predominantly oxidized and minimally esterified, whereas the reverse was found for LCFA. This observation probably explains why dietary LCFA, but not MCFA, accumulate in hepatic triglycerides, and why much less hepatic steatosis develops after feeding of alcohol with MCFA than with LCFA.

\section{Acknowledgment}

We are grateful to Dr. T. P. Almy for his continuous interest and support.

\section{References}

1. Lieber, C. S., A. Lefevre, L. Feinman, and N. Spritz. 1966. Importance of dietary long-chain fatty acids in the pathogenesis of the alcoholic fatty liver. Gastroenterology. 50: 856. (Abstr.)

2. Lieber, C. S., and N. Spritz. 1966. Effects of prolonged ethanol intake in man: role of dietary, adipose, and endogenously synthesized fatty acids in the pathogenesis of the alcoholic fatty liver. $J$. Clin. Invest. $45: 1400$.

3. Lieber, C. S., N. Spritz, and L. M. DeCarli. 1966. Role of dietary, adipose, and endogenously synthesized fatty acids in the pathogenesis of the alcoholic fatty liver. J. Clin. Invest. $45: 51$.

4. Lieber, C. S., and L. M. DeCarli. 1966. Study of agents for the prevention of the fatty liver produced by prolonged alcohol intake. Gastroenterology. 50 : 316.

5. Lieber, C. S., D. P. Jones, and L. M. DeCarli. 1965. Effects of prolonged ethanol intake: production of fatty liver despite adequate diets. J. Clin. Invest. 44 : 1009.

6. Miller, L. L., C. G. Bly, M. L. Watson, and W. F. Bale. 1951. The dominant role of the liver in plasma protein synthesis. J. Exptl. Med. 94 : 431.

7. Kay, R. E., and C. Entenman. 1961. The synthesis of "chylomicron-like" bodies and maintenance of normal blood sugar levels by the isolated, perfused rat liver. J. Biol. Chem. 236: 1006.

8. Fredrickson, D. S., D. L. McCollester, and K. Ono. 1958. The role of unesterified fatty acid transport in chylomicron metabolism. J. Clin. Invest. 37 : 1333.

9. Harlan, J. W. 1963. Liquid scintillation counting of $\mathrm{C}^{14} \mathrm{O}_{2}$ in aqueous carbonate solutions. Advan. Tracer Methodoly. 1 : 115.

10. Lieber, C. S., and R. Schmid. 1961. The effect of ethanol on fatty acid metabolism. Stimulation of hepatic fatty acid synthesis in vitro. J. Clin. Invest. 40: 394.

11. Van Slyke, D. D. 1917. Studies of acidosis. II. A method for the determination of carbon dioxide and carbonates in solution. J. Biol. Chem. 30: 347 .

12. Gornall, A. G., C. J. Bardawill, and M. M. David. 1949. Determination of serum proteins by means of the biuret reaction. J. Biol. Chem. 177: 751 .

13. Bonnichsen, R. 1963. Ethanol-determination with alcohol dehydrogenase and DPN. In Methods of Enzymatic Analysis. Hans-Ulrich Bergmeyer, editor. Academic Press Inc., New York. 285.

14. Stein, Y., and B. Shapiro. 1958. Glyceride synthesis by microsome fractions of rat liver. Biochim. Biophys. Acta. 30: 271.

15. Folch, J., M. Lees, and G. H. Sloane Stanley. 1957. A simple method for the isolation and purification of total lipids from animal tissues. J. Biol. Chem. 226: 497. 
16. Lowry, O. H., N. J. Rosebrough, A. L. Farr, and R. J. Randall. 1951. Protein measurement with the Folin phenol reagent. J. Biol. Chem. 193: 265.

17. Snedecor, G. W. 1956. Statistical Methods. Iowa State College Press, Ames, Iowa. 5th edition. 534.

18. Brady, R. O., and S. Gurin. 1950. The biosynthesis of radioactive fatty acids and cholesterol. J. Biol. Chem. 186: 461.

19. Bloom, B., I. L. Chaikoff, and W. O. Reinhardt. 1951. Intestinal lymph as pathway for transport of absorbed fatty acids of different chain lengths. Am. J. Physiol. 166 : 451.

20. Borgström, B. 1955 . Transport form of ${ }^{14} \mathrm{C}$-decanoic acid in porta and inferior vena cava blood during absorption in the rat. Acta Physiol. Scand. 34:71.

21. Morris, B. 1963. The metabolism of free fatty acids and chylomicron triglycerides by the isolated perfused liver of the rat. J. Physiol (London). 168: 564.

22. Felts, J. M., and P. A. Mayes. 1965. Lack of uptake and oxidation of chylomicron triglyceride to carbon dioxide and ketone bodies by the perfused rat liver. Nature. 206: 195.

23. Schotz, M. C., B. Arnesjö, and T. Olivecrona. 1966. The role of the liver in the uptake of plasma and chyle triglycerides in the rat. Biochim. Biophys. Acta. 125: 485.

24. Ontko, J. A., and D. B. Zilversmit. 1967. Metabolism of chylomicrons by the isolated rat liver. J. Lipid Res. 8: 90.
25. Boberg, J., L. A. Carlson, and L. Normell. 1964. Production of lipolytic activity by the isolated, perfused dog liver in response to heparin. Life Sci. 3: 1011 .

26. Jeffries, G. H. 1954. The sites at which plasma clearing activity is produced and destroyed in the rat. Quart. J. Exptl. Physiol. 39: 261.

27. Spitzer, J. A., and J. J. Spitzer. 1956. Effect of liver on lipolysis by normal and postheparin sera in the rat. Am. J. Physiol. 185: 18.

28. Morris, B., and J. E. French. 1958. The uptake and metabolism of $\mathrm{C}^{14}$ labelled chylomicron fat by the isolated perfused liver of the rat. Quart. $J$. Exptl. Physiol. 43: 180.

29. Mayes, P. A., and J. M. Felts. 1966. Demonstration of lipoprotein lipase in rat liver. Biochem. J. 99: 43P.

30. Lundquist, F., N. Tygstrup, K. Winkler, K. Mellemgaard, and S. Munck-Petersen. 1962. Ethanol metabolism and production of free acetate in the human liver. J. Clin. Invest. 41 : 955.

31. Lieber, C. S. 1966. Hepatic and metabolic effects of alcohol. Gastroenterology. 50: 119.

32. Kornberg, A., and W. E. Pricer, Jr. 1953. Enzymatic esterification of $\alpha$-glycerophosphate by long chain fatty acids. J. Biol. Chem. $204: 345$.

33. Dawson, A. M., and K. J. Isselbacher. 1960. Studies on lipid metabolism in the small intestine with observations on the role of bile salts. J. Clin. Invest. $39: 730$. 